\title{
Detection of Breathing Rates in Through-wall UWB Radar Utilizing JTFA
}

\author{
Xiaolin Liang ${ }^{1}$ and Yongling Jiang ${ }^{2, *}$ \\ ${ }^{1}$ Science and Technology on Electronic Test \& Measurement Laboratory, \\ The 41st Research Institute of CETC, 266555, Qingdao, China \\ [e-mail: xiaolin87liang@163.com] \\ ${ }^{2}$ Fundamental Computer Department, Ocean University of China, \\ 266100, Qingdao, China \\ [e-mail: yonglingjiang@ouc.edu.cn] \\ *Corresponding author: Yongling Jiang
}

Received March 8, 2019; revised April 22, 2019; accepted May 12, 2019; published November 30, 2019

\begin{abstract}
Through-wall ultra-wide band (UWB) radar has been considered as one of the preferred and non-contact technologies for the targets detection owing to the better time resolution and stronger penetration. The high time resolution is a result of a larger of bandwidth of the employed UWB pulses from the radar system, which is a useful tool to separate multiple targets in complex environment. The article emphasised on human subject localization and detection. Human subject usually can be detected via extracting the weak respiratory signals of human subjects remotely. Meanwhile, the range between the detection object and radar is also acquired from the 2D range-frequency matrix. However, it is a challenging task to extract human respiratory signals owing to the low signal to clutter ratio. To improve the feasibility of human respiratory signals detection, a new method is developed via analysing the standard deviation based kurtosis of the collected pulses, which are modulated by human respiratory movements in slow time. The range between radar and the detection target is estimated using joint time-frequency analysis (JTFA) of the analysed characteristics, which provides a novel preliminary signature for life detection. The breathing rates are obtained using the proposed accumulation method in time and frequency domain, respectively. The proposed method is validated and proved numerically and experimentally.
\end{abstract}

Keywords: through-wall radar; joint time-frequency analysis; respiratory

This research was funded by the Anhui Provincial Natural Science Foundation (1908085MF201), National Defense Innovation Special Zone Project (***005-01), National Key Research and Development Program (2018YFF0109302 and 2018YFF0109702), China Electronics Technology Group Corporation Innovation Fund (KJ1701008) and Science and Technology on Electronic Test \& Measurement Laboratory (614200103010117 and 614200105010217). 


\section{Introduction}

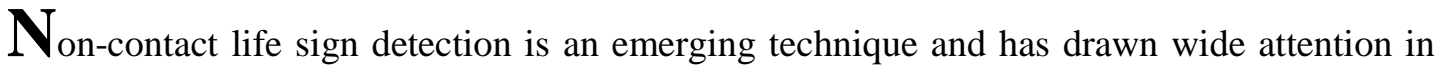
recent years [1-5]. Among many existing non-contact detection systems, the electromagnetic detection method is the most concerned technique for life sign detection due to the radar pulses are modulated by life activities such as human respiratory and heartbeat. Impulse ultra-wideband (UWB) radar has been widely applied to track moving targets, through-wall imaging and son on due to its excellent time resolution and strong permeability [6-13]. However, extensive researches on life sign detection need to be made based on UWB radar [14-22]. In [14], a contactless human subject monitoring system is designed using a Doppler radar based on a four-tiered layer structure. An omnidirectional detection system is designed and analyzed utilizing an antenna array technique [17]. The capability of the frequency modulated continuous wave (FMCW) radar for human respiratory signals detection is proven continuously and timely [19]. The performance of moving-target detection in UWB is validated based on the synthetic aperture radar (SAR) technique using the acquried single-channel SAR data [20]. The authors proposed an improved imaging system with a higher resolution via employing the UWB transmission, SAR technique, and multiple-input multiple-output (MIMO) array [21]. An improved MUltiple SIgnal Classification (MUSIC) algorithm is proposed for huamn subject detection based on a spatial smoothing decorrelation scheme [22].

Many algorithms for life sign detection have been proposed recently [23-42]. L. Liu analysed the time-frequency characteristic of human respiratory by employing the Hilbert transform based Fourier transform [23-24]. J. Wang investigated an extended detection method using differentiate and cross-multiply to eliminate the codomain restriction in the arctangent demodulation (AD) method [25]. Z. Li suppressed the respiratory-like clutters based on the adaptive clutter cancellation algorithm under a dual frequency model [26]. E. Conte estimated the real time estimation of life signs based on the maximum likelihood period estimator under Gaussian noise [28]. A. Nezirovic analysed the principal component analysis (PCA) technique to detect human subject under complex background, which can cause a low signal to clutter ratio [29]. H. Lv improved the feasibility for human respiration detection based on the data fusion from the multistatic UWB radar [30]. Y. Wang investigated the field-programmable gate arrays (FPGAs) to estimate human respiration in both time and frequency domain [31]. Z. Zhang developed a novel signal processing algorithm to achieve the range estimates between the survivor and top wall in post-disaster rescue [32]. Y. Xie proposed a tracing method for life sign detection [34]. A. Nezirovic removed the non-static clutters based on the linear trend subtraction (LTS) algorithm [35]. Y. Xu analyzed the results after suppressing Gaussian noise using the fourth order cumulant method [37]. X. Hu discussed human heartbeat signals via extracting life signs based on the intrinsic mode function [38]. B. K. Park performed the AD algorithm on improving the accuracy of heartbeat rate [40]. K. Naishadham proposed a state space method (SSM) model for life sign detection [41]. However, most algorithms are unsuitable to life sign detection because they can only deal with some aspects. As a result, it is challenging to acquire accurate life sign such as respiratory frequency in complex environments. It is necessary to develop a novel detection system for life sign detection which is effective even in low SNR.

An effective method is presented to achieve human respiratory movement extraction in a lower SNR condition. To improve feasibility of human respiratory movement detection, the 
distance between the radar and the volunteer is acquired using joint time-frequency analysis (JTFA), which provides a novel preliminary signature for life detection. Most importantly, an improved spectrum accumulation algorithm is developed to obtain life signals. The contributions of the proposed detection method are

(1) The joint time-frequency analysis (JTFA) method is developed to acquire the distance estimate after improving the SNR of the received UWB pulses.

(2) To estimate human respiratory rates, the time-window-selection based accumulation technique is presented to deal with the effects of noises.

The following article is constructed as: Sec. 2 provides the model for human respiratory movement detection. The method is given in Sec. 3. Sec. 4 provides the experimental results, and Sec. 5 summarizes the article.

\section{Life Model}

This section introduces the life model. By employing the ultra-wide band (UWB) radar, living persons can be extracted based on the changing time delay of pulses modulated by human respiratory movement. The distance is [27]

$$
d(t)=d_{0}+r(t)=d_{0}+A_{r} \sin \left(2 \pi f_{r} t\right)
$$

where $t$ is names as slow time, which is used for frequency estimation of life activities, $d_{0}$ is the range between the through-wall radar and the volunteer, $A_{r}$ is the amplitude of huamn breathing movement, and $f_{r}$ is the rate of huamn breathing movement.

When there is only one living person and stationary subjects in environments, the responses are

$$
h(\tau, t)=a_{v} \delta\left(\tau-\tau_{v}(t)\right)+\sum_{m} a_{m} \delta\left(\tau-\tau_{m}\right) .
$$

where $\tau$ represents the named as fast-time, $m$ represents the static target number, $\sum_{m} a_{m} \delta\left(\tau-\tau_{m}\right)$ are joined responses from the stationary subjects with time delay $\tau_{m}$ and amplitude $a_{m}, a_{v} \delta\left(\tau-\tau_{v}(t)\right)$ is the responses from the living person with amplitude $a_{v}$ and time delay $\tau_{v}(t)$, which can be expressed as [33]

$$
\tau_{v}(t)=\frac{2 d(t)}{v}=\tau_{0}+\tau_{r} \sin \left(2 \pi f_{r} t\right)
$$

where $v=3 \times 10^{8} \mathrm{~m} / \mathrm{s}$, and $\tau_{r}=2 A_{r} / v$.

Using UWB radar, the collected pulses in digital form are

$$
R(i, j)=a_{v} s\left(i \psi_{R}-v \tau_{v}\left(j T_{s}\right)\right)+\sum_{m} a_{i} s\left(i \psi_{R}-v \tau_{m} / 2\right)
$$


In real environment, (4) can be amended as

$$
\mathbf{R}=\boldsymbol{\alpha}+\boldsymbol{\beta}+\boldsymbol{\mu}+\boldsymbol{\rho}+\boldsymbol{\varphi}+\boldsymbol{\kappa}+\mathbf{Z}
$$

where $\boldsymbol{\alpha}$ represents life signs, $\boldsymbol{\beta}$ represents the static clutter, $\boldsymbol{\mu}$ represents the possible linear trend, $\boldsymbol{\rho}$ represents the Gaussian noise, $\boldsymbol{\varphi}$ represents the nonstatic clutter, $\boldsymbol{\kappa}$ represents the some unknown noise, and $\mathbf{z}$ represents the noises from moving targets, $1 / T_{s}$ represents the pulse repetition frequency with $t=j T_{s}, j=0,1, \ldots, J-1,1 / \delta_{T}$ represents the sampling period of $\tau$ with $i=0,1, \ldots, I-1 . \psi_{R}=v \psi_{T} / 2$ represents the sampling period of distance.

Usually, based on FFT method, the rates of human respiratory movements can be acquired, which can be given by

$$
Y\left(m \delta_{T}, f\right)=\int_{-\infty}^{+\infty} Y(v, f) e^{j 2 \pi v \tau} d v
$$

where $Y(v, f)$ stands for the 2D FFT of (5), $v$ is the frequency component of $\tau$

$$
\begin{gathered}
Y(v, f)=\int_{-\infty}^{+\infty} \int_{-\infty}^{+\infty} \widetilde{R}\left(m \delta_{T}, t\right) e^{-j 2 \pi f t} e^{-j 2 \pi v \tau} d t d \tau . \\
Y(v, f)=\int_{-\infty}^{+\infty} a_{v} S(v) e^{-j 2 \pi f t} e^{-j 2 \pi v \tau_{v}(t)} d t \\
=a_{v} S(v) e^{-j 2 \pi v \tau_{0}} \int_{-\infty}^{+\infty} e^{-j 2 \pi v m_{b} \sin \left(2 \pi f_{r} t\right)} e^{-j 2 \pi v m_{h} \sin \left(2 \pi f_{h} t\right)} e^{-j 2 \pi f t} d t
\end{gathered}
$$

where $S(v)$ is the frequency of the UWB pulse.

Using Bessel functions, (8) is given by

$$
\begin{gathered}
Y(v, f)=a_{v} S(v) e^{-j 2 \pi v \tau_{0}} \int_{-\infty}^{+\infty}\left(\sum_{k=-\infty}^{+\infty} J_{k}\left(\beta_{r} v\right) e^{-j 2 \pi k f_{r} t}\right)\left(\sum_{l=-\infty}^{+\infty} J_{l}\left(\beta_{h} v\right) e^{-j 2 \pi f_{b} t}\right) e^{-j 2 \pi f t} d t . \\
e^{-j z \sin \left(2 \pi f_{0} t\right)}=\sum_{k=-\infty}^{+\infty} J_{k}(z) e^{-j 2 \pi k f_{0} t} .
\end{gathered}
$$

where $\beta_{r}=2 \pi A_{r}$ and $\beta_{h}=2 \pi A_{h}$. 
(6) is given by

$$
Y\left(m \delta_{T}, f\right)=a_{v} \sum_{k=-\infty}^{+\infty} \sum_{l=-\infty}^{+\infty} G_{k l}(\tau) \delta\left(f-k f_{r}-l f_{h}\right)
$$

where

$$
G_{k}(\tau)=\int_{-\infty}^{+\infty} S(v) J_{k}\left(\beta_{r} v\right) J_{l}\left(\beta_{h} v\right) e^{j 2 \pi v\left(\tau-\tau_{0}\right)} d v
$$

The maximum (12) is expressed as

$$
\begin{gathered}
C_{k l}=G_{k l}\left(\tau_{0}\right)=\int_{-\infty}^{+\infty} S(v) J_{k}\left(\beta_{r} v\right) J_{l}\left(\beta_{h} v\right) d v \\
Y\left(\tau_{0}, f\right)=a_{v} \sum_{k=-\infty}^{+\infty} \sum_{l=-\infty}^{+\infty} C_{k l} \delta\left(f-k f_{r}-l f_{h}\right) .
\end{gathered}
$$

Utilizing (14), the harmonics of human respiratory signals is given by

$$
C_{k 0}=\int_{-\infty}^{+\infty} S(v) J_{k}\left(\beta_{r} v\right) J_{0}\left(\beta_{h} v\right) d v
$$

\section{Developed Algorithm}

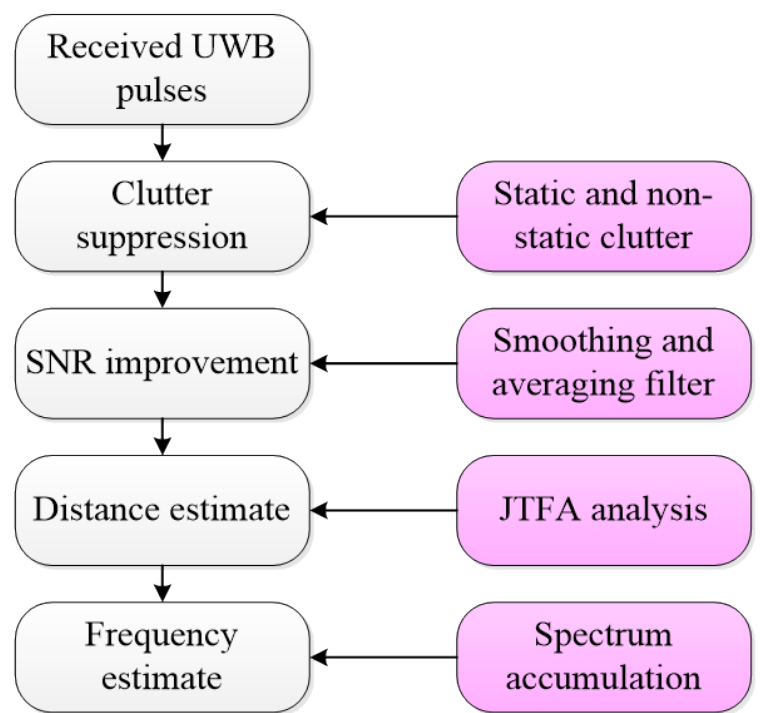

Fig. 1. The developed detection algorithm for through-wall human subject. 
The developed algorithm is shown in Fig. 1. In the proposed method, JTFA method is developed to acquire the distance estimate after improving SNR of the received UWB pulses. To estimate human respiratory rates, the time-window-selection based accumulation technique is presented to deal with the effects of noises.

\subsection{Clutter Suppression}

This section employs the time mean subtraction (TMS) technique to acquire $\boldsymbol{\beta}$ estimate, which is expressed as

$$
\mathfrak{I}=\frac{1}{I \times J} \sum_{i=1}^{J} \sum_{i=1}^{J} R[i, j]
$$

Via removing $\boldsymbol{\beta}$, we can obtain

$$
\Omega_{M \times N}=R_{M \times N}-\mathfrak{J}
$$

LTS method is applied on suppressing $\boldsymbol{\mu}$. The following results are acquired

$$
\mathbf{W}=\mathbf{\Omega}^{\mathrm{T}}-\mathbf{X}\left(\mathbf{X}^{\mathrm{T}} \mathbf{X}\right)^{-1} \mathbf{X}^{\mathrm{T}} \mathbf{\Omega}^{\mathrm{T}},
$$

where $\mathbf{X}=\left[\mathbf{x}_{1}, \mathbf{x}_{2}\right], \mathbf{x}_{1}=[0,1, \ldots . ., J-1]^{\mathrm{T}}$, and $\mathbf{x}_{2}=[1,1, \ldots ., 1]_{J \times 1}^{\mathrm{T}}$.

\subsection{SNR Improvement}

In the radar system, we usually cannot achieve the maximum value of SNR by employing the traditional matched filter [36]. To improve SNR, another alternative technique is required i.e. one band pass filter is employed in this paper. By employing the fifth filter, we can acquire

$$
\mathbf{S}=\mathbf{Q W}-\mathbf{R} \mathbf{W}
$$

where $\mathbf{Q}$ and $\mathbf{R}$ are filter coefficients.

And one smoothing filter is also used for SNR improvement as

$$
\Phi[k, j]=\frac{1}{\lambda} \sum_{i=\lambda k}^{\lambda(k+1)-1} S[i, j]
$$

where $k=1, \cdots,\lfloor M / \lambda\rfloor,\lfloor M / \lambda\rfloor$ is the largest integer less than $M / \lambda$, and $\lambda=7$.

\subsection{Distance Estimation}

An improved method for distance estimation is presented by calculating the standard deviation (SD) based kurtosis spectral of life signals [43]. For each $\tau$ index $i$ in (20), the kurtosis value can be given by

$$
K=\mathrm{E}\left[\left(\Phi_{I \times J}[i, J]\right)^{4}\right] /\left\{\mathrm{E}\left[\left(\Phi_{I \times J}[i, J]\right)^{2}\right]\right\}^{2}
$$

where $\mathrm{E}[]$ is the mathematical expectation, $\mu$ is mean and $\sigma$ is standard deviation. 
$\mathrm{SD}$ is

$$
S D=\sqrt{\sum_{j=1}^{J}\left(\Phi_{\mathrm{I} \times \mathrm{J}}[i, j]-\mu\right)^{2} / J-1}
$$

The spectral kurtosis value is considered as an effective tool to acquire presence of a periodic signal in frequency domain [44]. For a periodic signal, the kurtosis meets the same period. To show the characteristics of life signs, one dataset is acquired in an indoor environment, where a man acted as the detection target with a range between radar and him being $7 \mathrm{~m}$. This paper discusses SD based spectral kurtosis i.e. the product of SD and kurtosis considered as KSD using JTFA, which can be used for life detection. Fig. 2(c) shows KSD $\left(\Psi_{M \times 1}\right)$. We can see that KSD meets a periodicity in target area. Fig. 2(b) shows $\Psi$ when there is no human subject. Results indicate $\Psi$ variates randomly compared with Fig. 2(a).

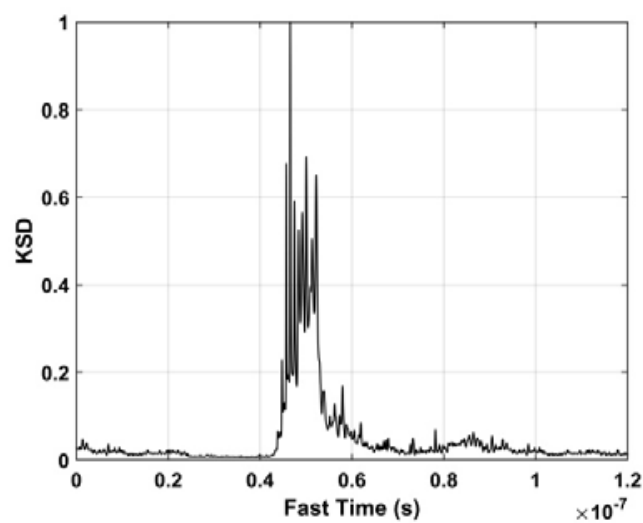

(a)

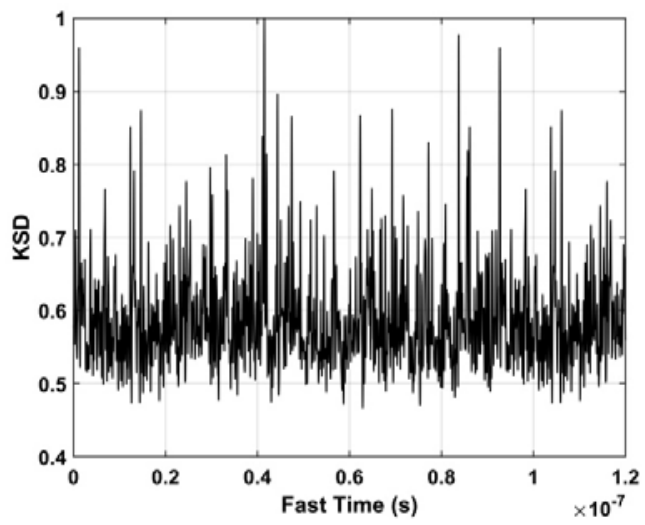

(c)

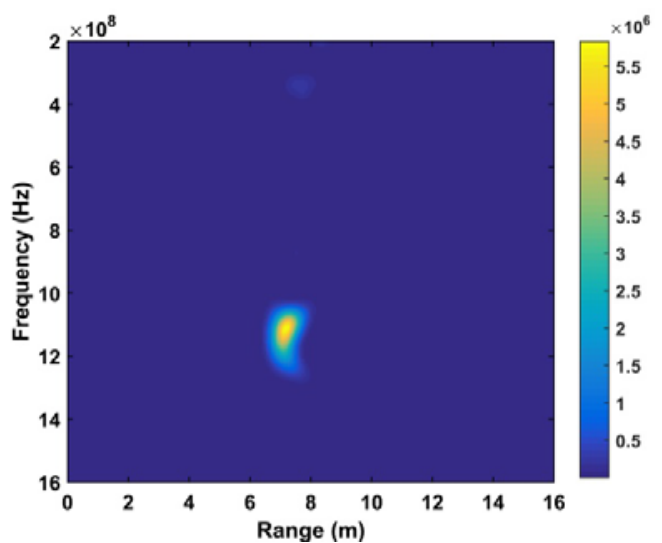

(b)

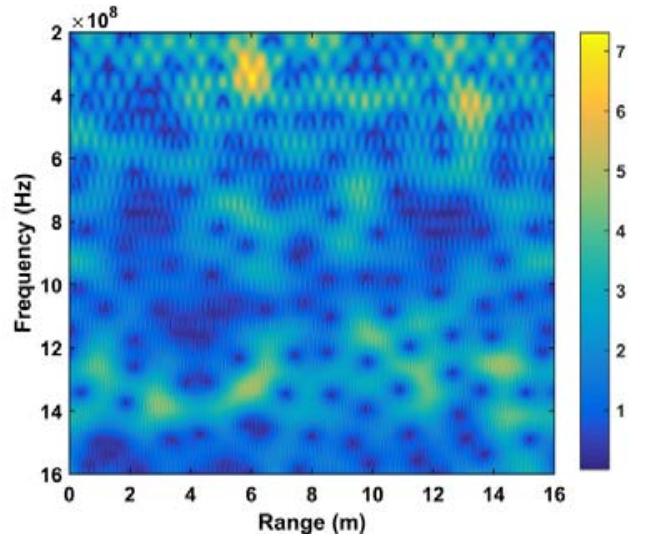

(d)

Fig. 2. (a) KSD values using the dataset at a distance of $7 \mathrm{~m}$; (b) Time-frequency matrix using JTFA; (c) KSD values using the dataset without human subject; and (d) Time-frequency matrix using JTFA without human subject. 

$\Psi[45]$

To acquire distance estimation, the short-time Fourier transform (STFT) is performed on

$$
K[\Lambda, \Xi]=\sum_{i=1}^{I} \widehat{\Psi}[i, 1] \Xi[\Lambda-i] e^{-j 2 \Theta \pi i / P}
$$

where the using windowing function $\Xi$ is given by

$$
\Xi(\Lambda)=\varepsilon-\varpi \cos \left(\frac{2 \pi \Lambda}{O}\right), \quad \Lambda=0,1, \cdots, O
$$

where $\varepsilon=0.45, \varpi=0.54$, and $O=512$ [46-47].

The results using JTFA based on the data as in Fig. 2(a) are shown in Fig. 2(b), while the results using STFT based on the data as in Fig. 2(c) are given in Fig. 2(d). Compared these two figures, the distance is

$$
\hat{L}=v \chi / 2
$$

where $\chi$ is time estimation respect to maximum in (23).

\subsection{Frequency Estimation}

Using the fast time estimation in (25), the time index is

$$
\mathfrak{I}=\chi / \delta_{T}
$$

To obtain the rate of human breathing movement, the cumulative in $\tau$ is used, which is given by

$$
\widetilde{O}[i]=\sum_{i=\mathfrak{\Im}-50}^{\mathfrak{S}}|\Phi[i, n]|^{2}
$$

$\mathrm{RF}$ is usually within $0.2-0.5 \mathrm{~Hz}$, a rectangular window is employed as

$$
\Omega[j]=\aleph[j]\left\{\operatorname{DFT}\left\{\widetilde{O}_{1 \times J}\right\}\right\}
$$

The rate is

$$
f_{r}=w\left(\mu_{r}\right), \quad w \in(0.1,0.8)
$$

where $\mu_{r}$ represents the corresponding index of the maximal value of (28).

To suppress harmonics in (28), the spectrum accumulation algorithm is developed, which is given by

$$
\delta[n]=l[n]+j l[n]
$$

where 


$$
l[n]= \begin{cases}2 \Omega[n], & \kappa>0 \\ \Omega[n], & \kappa=0 \\ 0, & \kappa<0\end{cases}
$$

Table 1 shows the results after performing the accumulation method for manifold cycles. We can see that unwanted components are eliminated sufficiently when the method is performed the fourth cycle even when it performed more cycles. As a result, this paper used the accumulation method for four times.

Table 1. Clutter suppression using the accumulation method

\begin{tabular}{|c|c|c|c|c|c|}
\hline Algorithm & FFT & First cycle & Second cycle & Fourth cycle & Sixth cycle \\
\hline \hline SNR (dB) & -12.4 & 0.506 & 1.27 & 6.14 & 6.75 \\
\hline
\end{tabular}

\section{Results and Discussion}

\subsection{Radar System}

The used through-wall radar to collect the pulses is shown in Fig. 3. One transmitter and one receiver are used in the system. The wireless personal digital assistant is used to transmit the collected pulses to a computer. For the through-wall radar, the center frequency of the generated pulse is $400 \mathrm{MHz}$ with a repeat frequency of $600 \mathrm{KHz}$, the sampling frequency in $\mathrm{t}$ is $29 \mathrm{~Hz}, 512$ pulses can be acquired within $17.6 \mathrm{~s}$. This through-wall radar works with the centre frequency $0.4 \mathrm{GHz}$ and pulse repetition frequency $0.6 \mathrm{MHz}$.

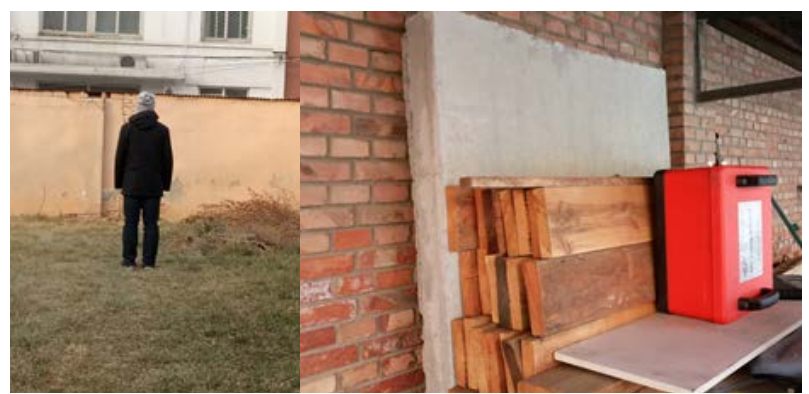

(a)

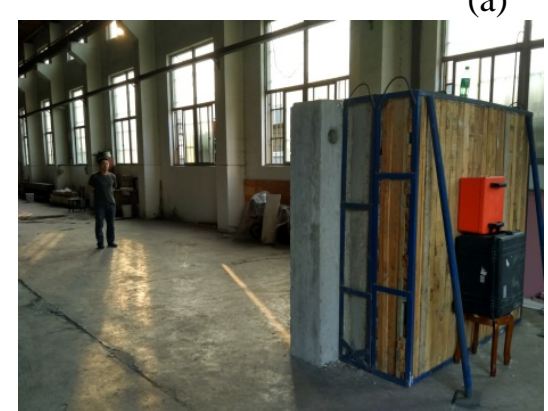

(b)

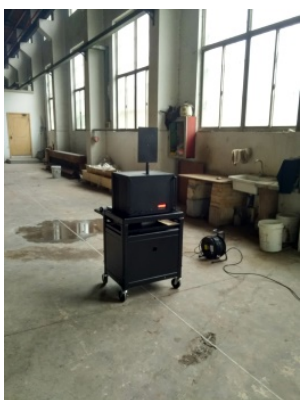

(c)

Fig. 3. Measurement setup for data acquisition (a) in outdoor environments; (b) in indoor environments; and (c) the used actuator. 


\subsection{Data Acquisition}

To validate the developed algorithm, different data sets are obtained. To conduct the experiments, the through-wall radar is at a height of $150 \mathrm{~cm}$. The wall between human target and through-wall radar is $100 \mathrm{~cm}$ in thickness. All detection targets facing the radar straightly breathed evenly and kept static. In the first experiment, one volunteer stood at different distances away from the through-wall radar as given in Fig. 3(a). Fig. 3(b) shows the second experiment, one detection target stood at different distances away from the through-wall radar. In the final experiment, one actuator is used to simulate human respiratory motion with a 0.33 $\mathrm{Hz}$ frequency and $3 \mathrm{~mm}$ amplitude at distances of $600 \mathrm{~cm}$ and $1000 \mathrm{~cm}$ as shown in Fig. 3(c).

\subsection{Intuitive Performance}

This section provides the results after clutter suppression using the data acquired from the volunteer at $600 \mathrm{~cm}$ in an indoor environment. Fig. 4(a) shows the results after removing static clutter based on TMS. Fig. 4(b) provides the results acquired from LTS, which shows that human respiratory signal is weak enough not to be identified. As shown in Fig. 4(c), life signal is enhanced effectively based on the band pass filter. The results acquired from the smoothing filter are shown in Fig. 4(d). Compared with Figs 4(a)-(c), it is much more easier to detect.

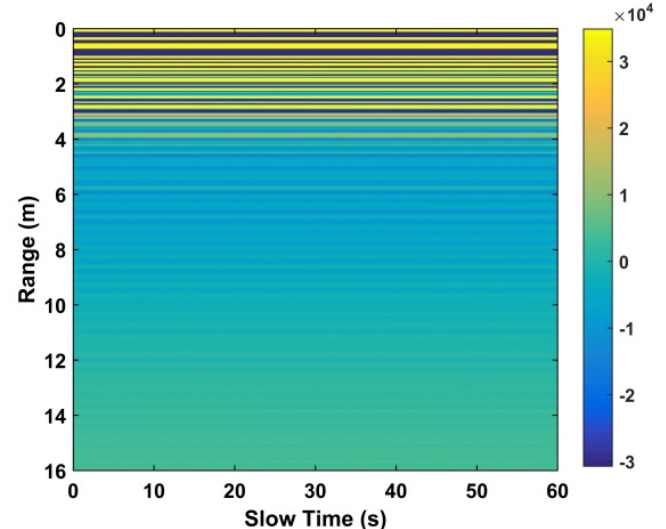

(a)

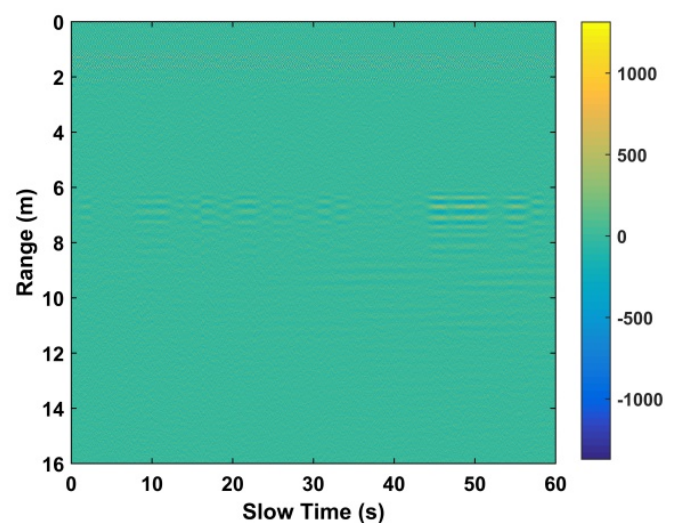

(c)

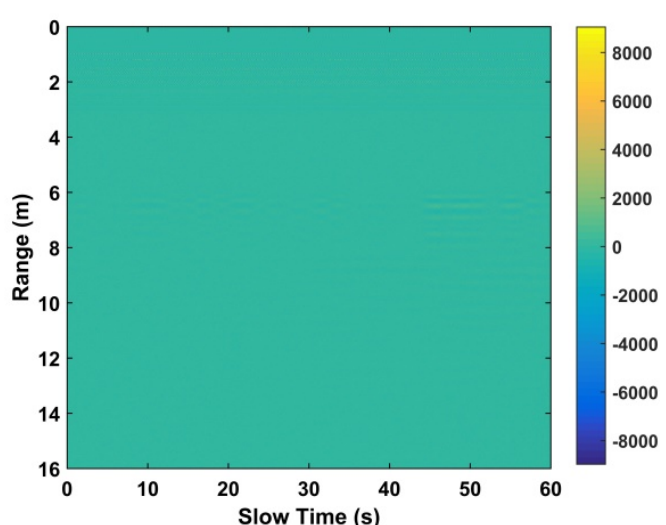

(b)

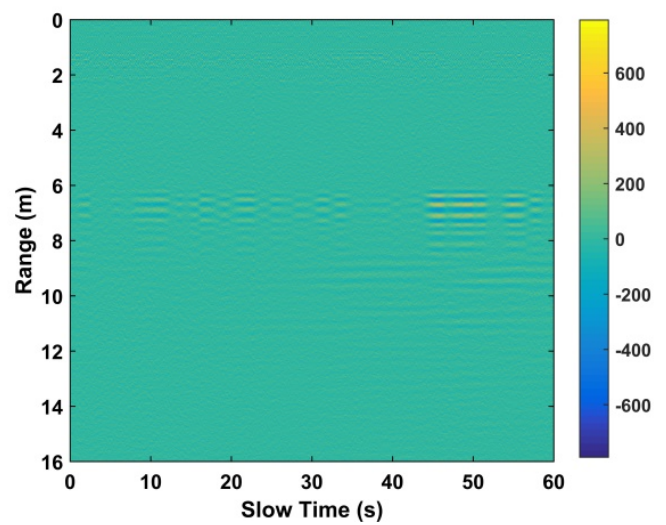

(d)

Fig. 4. The intuitive performance using dataset acquired at $600 \mathrm{~cm}$ using (a) TMS; (b) LTS; (c) BPF; and (d) smoothing filter method. 


\subsection{Performance in Outdoor Environment}

Using the acquired data at different ranges, the performance of the developed algorithm is proved. Fig. 5 shows the KSD values, and the distance estimations form the STFT are shown in Fig. 6. The KSD values meet periodicity in target area compared with that in non-target area. As shown in Table 2, the calculated errors are $7.9 \mathrm{~cm}(300 \mathrm{~cm})$ as in Fig. 5(a), $11.3 \mathrm{~cm}$ (600 $\mathrm{cm})$ as in Fig. 5(b), $8.4 \mathrm{~cm}(900 \mathrm{~cm})$ as in Fig. 5(c), and $24 \mathrm{~cm}(1100 \mathrm{~cm})$ as in Fig. 5(d). The frequency estimations are $0.2308 \mathrm{~Hz}(300 \mathrm{~cm})$ as in Fig. 6(a), $0.2307 \mathrm{~Hz}(600 \mathrm{~cm})$ as in Fig. 6(b), $0.2932 \mathrm{~Hz}(900 \mathrm{~cm})$ as in Fig. 6(c), and $0.3329 \mathrm{~Hz}(1100 \mathrm{~cm})$ as in Fig. 6(d). Accurate distance and frequency estimations can be achieved compared with the advanced method (AM) in [36]. SNR can be estimated as [37].

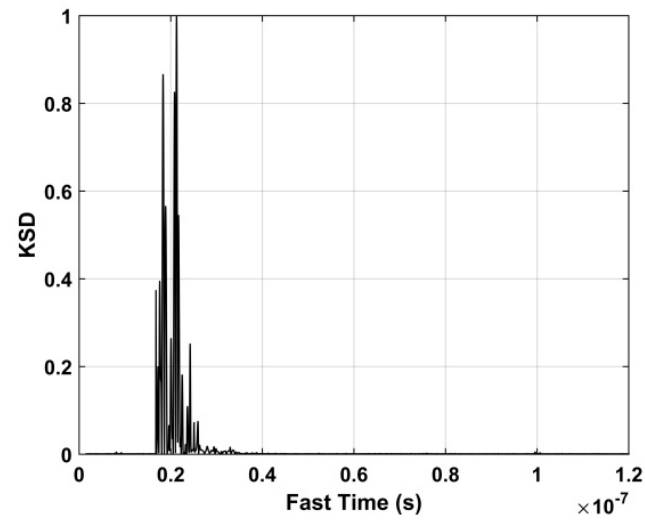

(a)

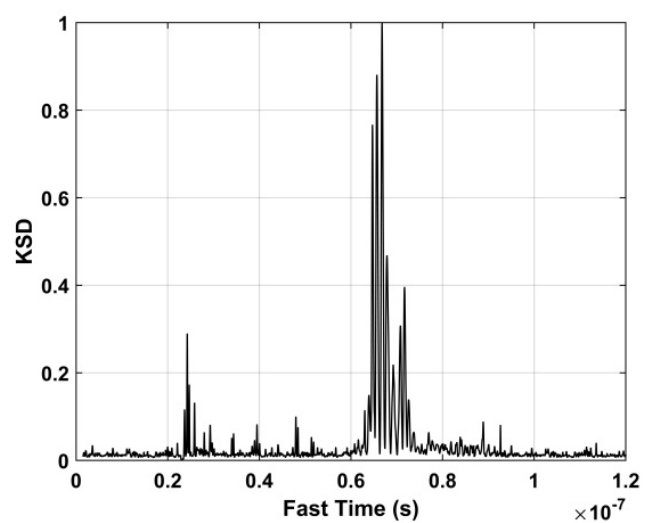

(c)

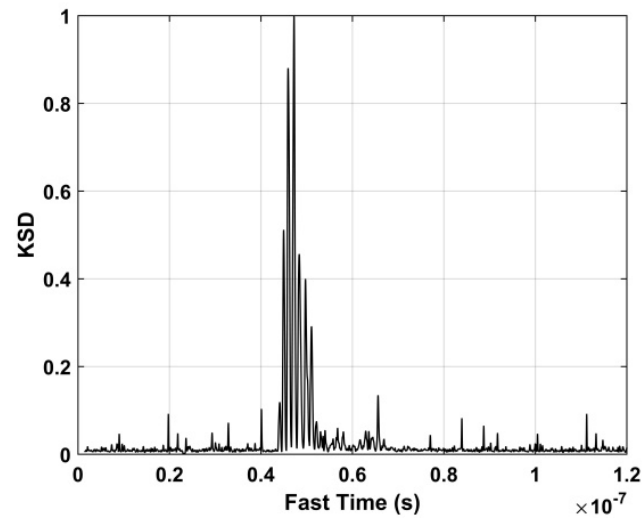

(b)

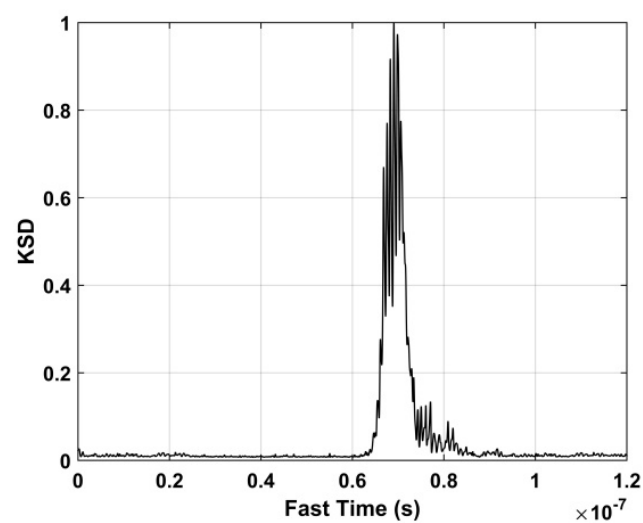

(d)

Fig. 5. KSD values at different ranges. 
The calculated SNR based on the developed algorithm is $5.62 \mathrm{~dB}(3 \mathrm{~m}), 4.82 \mathrm{~dB}(6 \mathrm{~m}), 2.17$ $\mathrm{dB}(9 \mathrm{~m})$, and $2.12 \mathrm{~dB}(11 \mathrm{~m})$. And SNR based on AM is $2.78 \mathrm{~dB}(3 \mathrm{~m}),-5.04 \mathrm{~dB}(6 \mathrm{~m}),-14.29$ $\mathrm{dB}(9 \mathrm{~m})$, and $-15.64 \mathrm{~dB}(11 \mathrm{~m})$. As a result, the developed algorithm can improve SNR effectively, which makes life easy to extract.

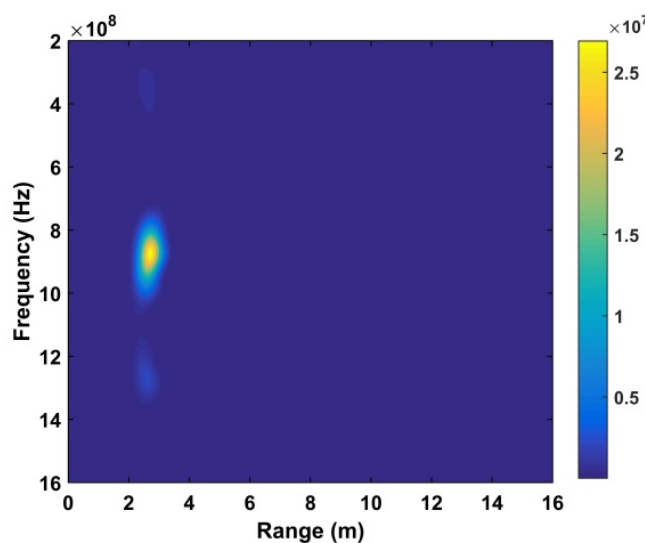

(a)

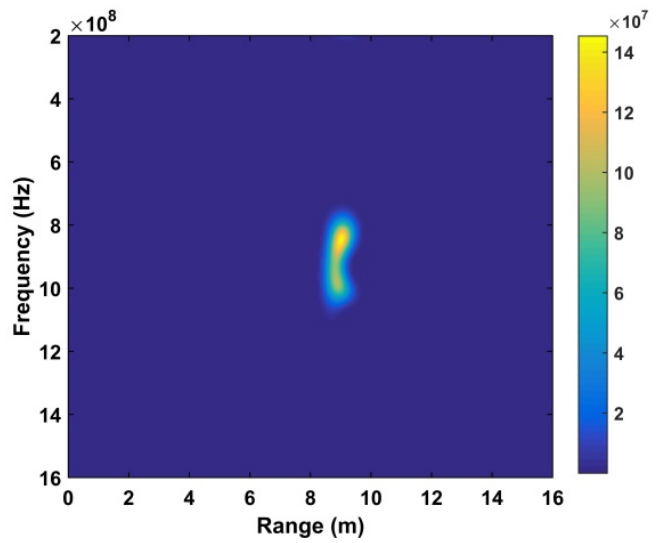

(c)

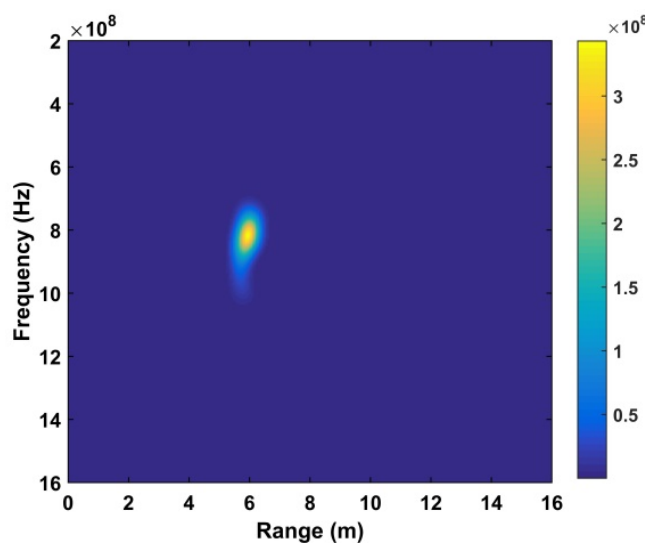

(b)

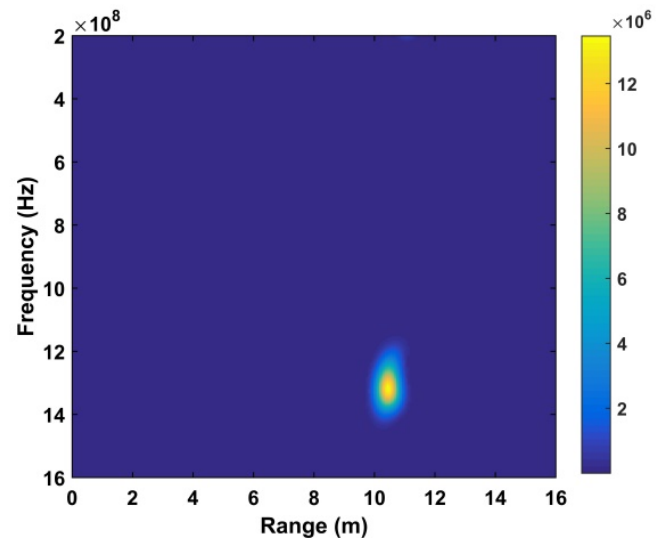

(d)

Fig. 6. Range estimates using JTFA at different ranges.

Table 2. Parameter estimates using two different algorithms.

\begin{tabular}{|l|l|l|l|l|l|}
\hline \multicolumn{2}{|l}{ Methods } & $300 \mathrm{~cm}$ & $600 \mathrm{~cm}$ & $900 \mathrm{~cm}$ & $1100 \mathrm{~cm}$ \\
\hline \hline \multirow{3}{*}{ Proposed } & Distance & $308 \mathrm{~cm}$ & $611 \mathrm{~cm}$ & $908 \mathrm{~cm}$ & $1124 \mathrm{~cm}$ \\
\cline { 2 - 6 } & Rate & $0.23 \mathrm{~Hz}$ & $0.23 \mathrm{~Hz}$ & $0.29 \mathrm{~Hz}$ & $0.33 \mathrm{~Hz}$ \\
\cline { 2 - 6 } & SNR & $6.1 \mathrm{~dB}$ & $5.2 \mathrm{~dB}$ & $1.9 \mathrm{~dB}$ & $2.2 \mathrm{~dB}$ \\
\hline \multirow{3}{*}{ AM } & Distance & $394 \mathrm{~cm}$ & $686 \mathrm{~cm}$ & $384 \mathrm{~cm}$ & $1858 \mathrm{~cm}$ \\
\cline { 2 - 6 } & Rate & $0.09 \mathrm{~Hz}$ & $0.20 \mathrm{~Hz}$ & $0.15 \mathrm{~Hz}$ & $0.79 \mathrm{~Hz}$ \\
\cline { 2 - 6 } & SNR & $3.1 \mathrm{~dB}$ & $-4.7 \mathrm{~dB}$ & $-13.38 \mathrm{~dB}$ & $-14.9 \mathrm{~dB}$ \\
\hline
\end{tabular}




\subsection{Performance Indoors}

Using the acquired data at different ranges, the performance is proved again. Fig. 7 provides KSD values, and the distance estimates using STFT are given in Fig. 8. As shown in Table 4, the errors are $6 \mathrm{~cm}(400 \mathrm{~cm})$ as in Fig. 8(a), $6 \mathrm{~cm}(700 \mathrm{~cm})$ as in Fig. 8(b), $11 \mathrm{~cm}(1000 \mathrm{~cm})$ as in Fig. 8(c), and $20 \mathrm{~cm}(1200 \mathrm{~cm})$ as in Fig. 8(d). The frequency estimates are $0.32 \mathrm{~Hz}(400$ $\mathrm{cm}), 0.26 \mathrm{~Hz}(700 \mathrm{~cm}), 0.29 \mathrm{~Hz}(1000 \mathrm{~cm})$, and $0.26 \mathrm{~Hz}(1200 \mathrm{~cm})$. The methods including AM [36], CFAR [37], and FOC [33] are used as references to compare with the presented algorithm. All results show the excellent capability of improving SNR, clutter and harmonic suppression.

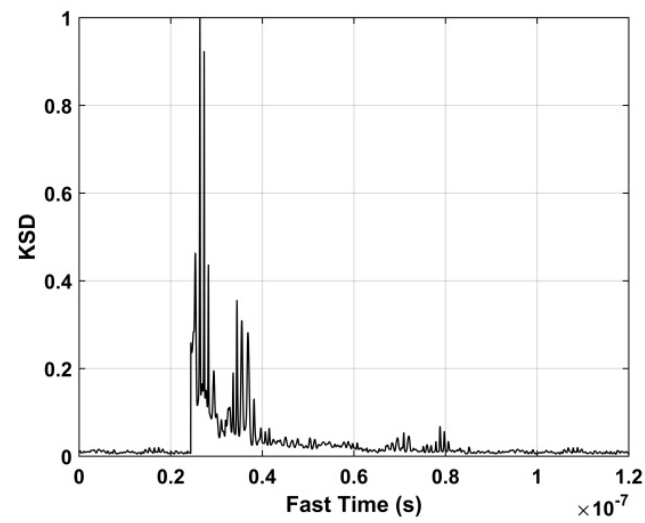

(a)

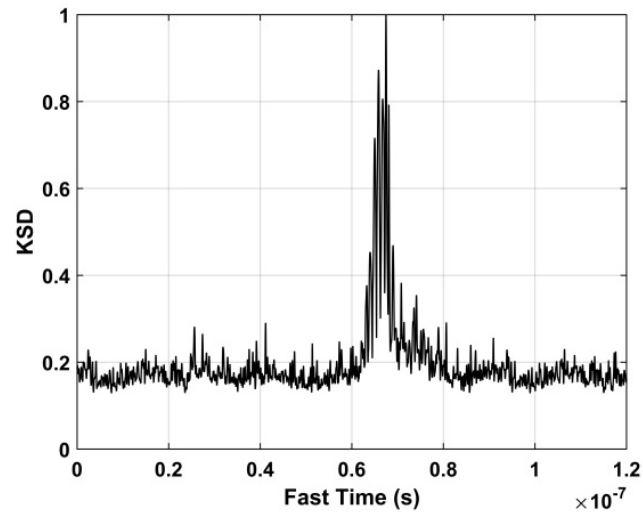

(c)

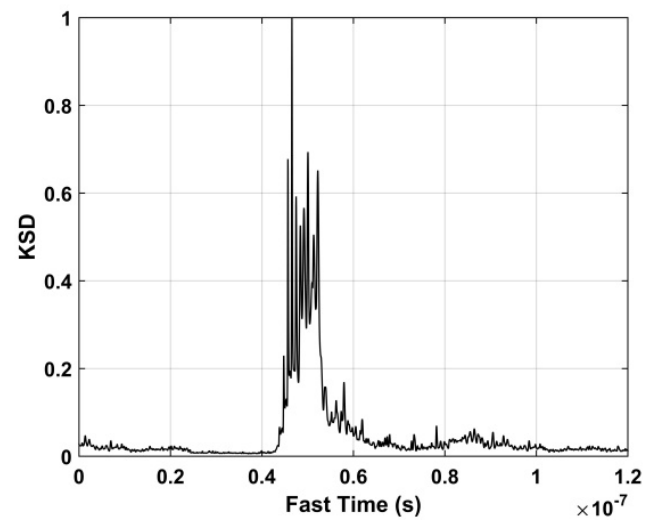

(b)

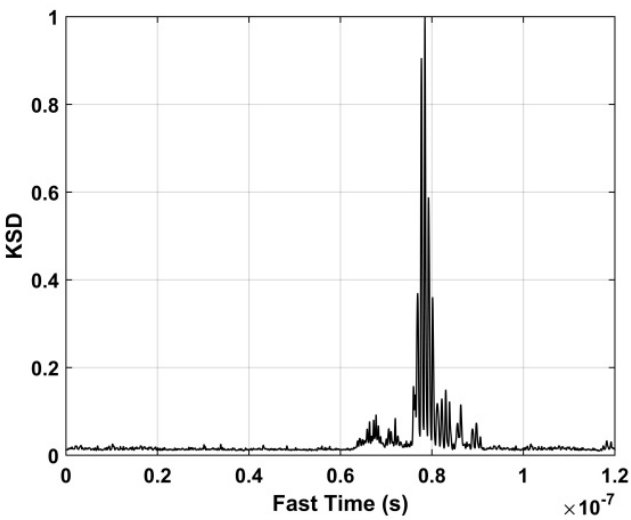

(d)

Fig. 7. KSD values using dataset acquired at different ranges. 


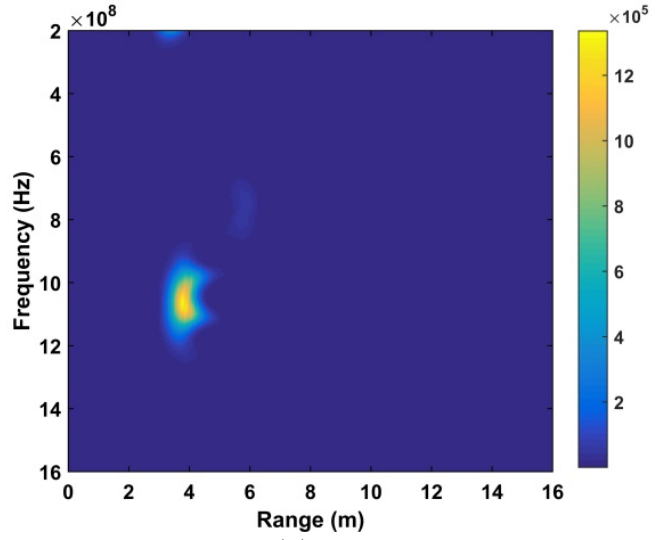

(a)

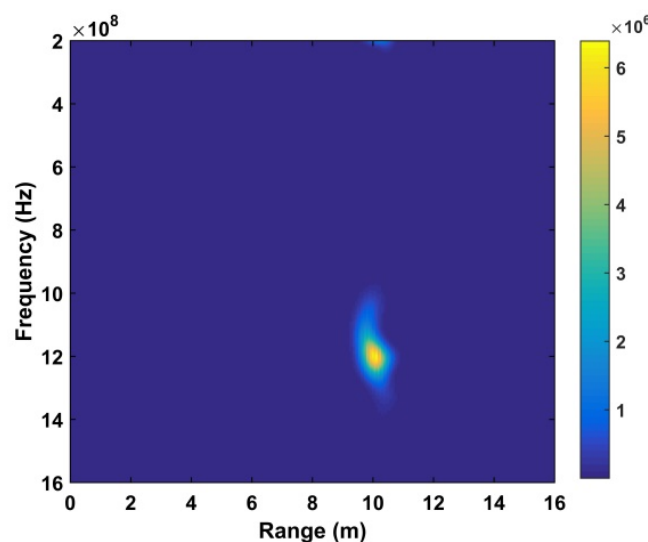

(c)

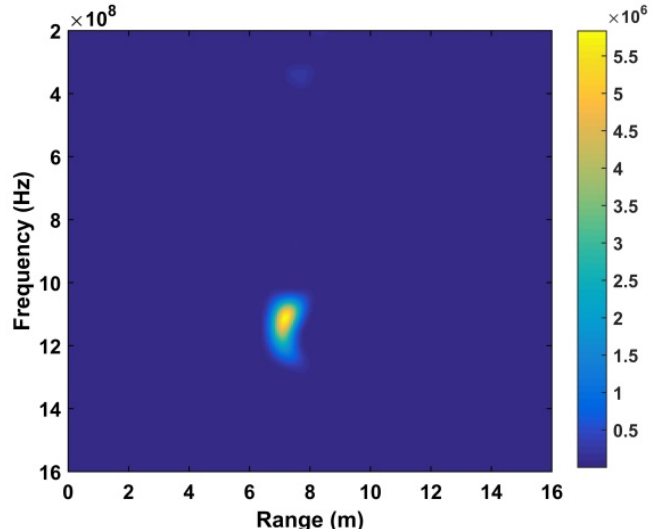

(b)

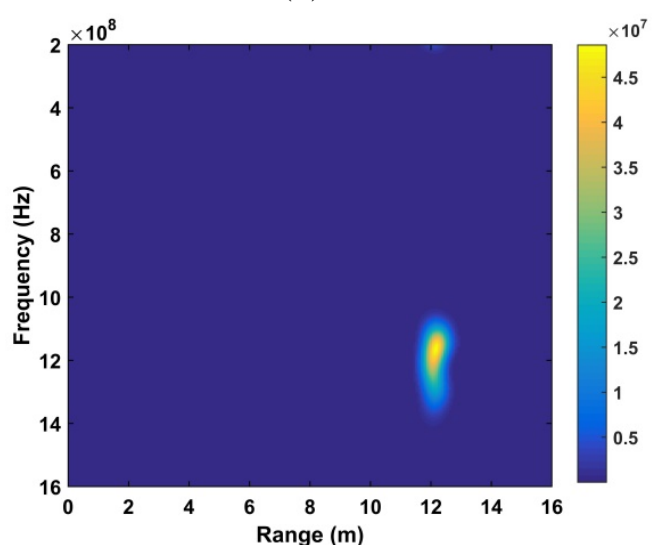

(d)

Fig. 8. Range estimates using STFT at different ranges.

Table 3. Parameter estimates with four different methods

\begin{tabular}{|c|c|c|c|c|c|}
\hline \multicolumn{2}{|c|}{ Methods } & $400 \mathrm{~cm}$ & $700 \mathrm{~cm}$ & $1000 \mathrm{~cm}$ & $1200 \mathrm{~cm}$ \\
\hline \hline \multirow{2}{*}{ CFAR } & Error & $27 \mathrm{~cm}$ & $436 \mathrm{~cm}$ & $672 \mathrm{~cm}$ & $954 \mathrm{~cm}$ \\
\cline { 2 - 6 } & Frequency & $0.18 \mathrm{~Hz}$ & $0.10 \mathrm{~Hz}$ & $0.72 \mathrm{~Hz}$ & $0.46 \mathrm{~Hz}$ \\
\hline \multirow{2}{*}{ Proposed } & Error & $6 \mathrm{~cm}$ & $6 \mathrm{~cm}$ & $11 \mathrm{~cm}$ & $20 \mathrm{~cm}$ \\
\cline { 2 - 6 } & Frequency & $0.32 \mathrm{~Hz}$ & $0.26 \mathrm{~Hz}$ & $0.29 \mathrm{~Hz}$ & $0.26 \mathrm{~Hz}$ \\
\hline \multirow{2}{*}{ FOC } & Error & $35 \mathrm{~cm}$ & $243 \mathrm{~cm}$ & $156 \mathrm{~cm}$ & 725 \\
\cline { 2 - 6 } & Frequency & $0.14 \mathrm{~Hz}$ & $0.45 \mathrm{~Hz}$ & $0.52 \mathrm{~Hz}$ & $0.44 \mathrm{~Hz}$ \\
\hline \multirow{2}{*}{$\mathrm{AM}$} & Error & $24 \mathrm{~cm}$ & $546 \mathrm{~cm}$ & $467 \mathrm{~cm}$ & $398 \mathrm{~cm}$ \\
\cline { 2 - 6 } & Frequency & $0.37 \mathrm{~Hz}$ & $0.12 \mathrm{~Hz}$ & $0.74 \mathrm{~Hz}$ & $0.63 \mathrm{~Hz}$ \\
\hline
\end{tabular}

\subsection{Actuator Experiment}

This section employs the dataset acquired from the actuator to provide the detection results of the analyzed method. The KSD values at different distances are shown in Figs. 9 (a)-(b). Distance estimates using STFT are shown in Figs. 9 (c)-(d). Based on the dataset acquired at $1000 \mathrm{~cm}$, the actuator frequency is $0.3337 \mathrm{~Hz}$ using the developed algorithm as shown in Table 3 with the error is only $0.0004 \mathrm{~Hz}$. The frequency estimation is $0.1155 \mathrm{~Hz}$ based on FFT with the deviation $65.35 \%$. Compared with FFT, the new method can improve SNR effectively as shown in Table 4. 


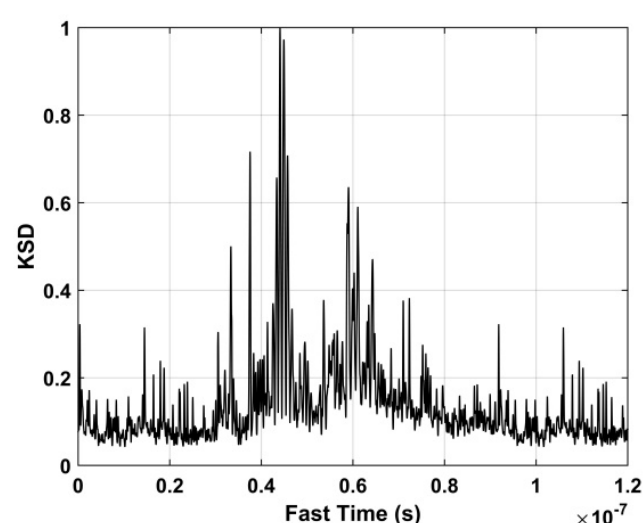

(a)

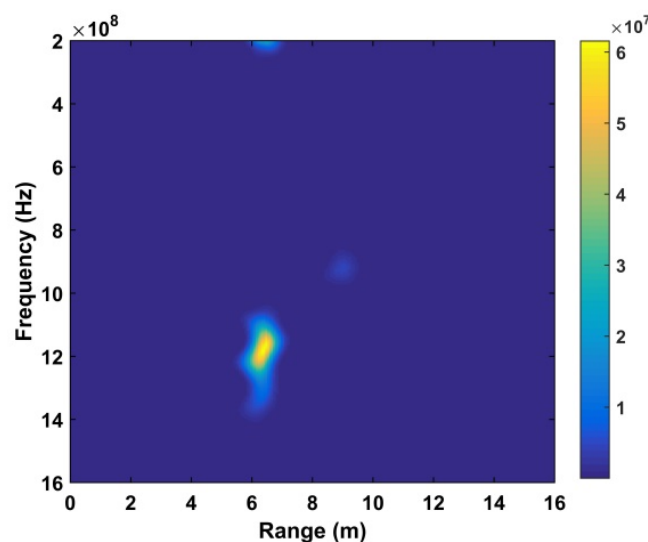

(a)

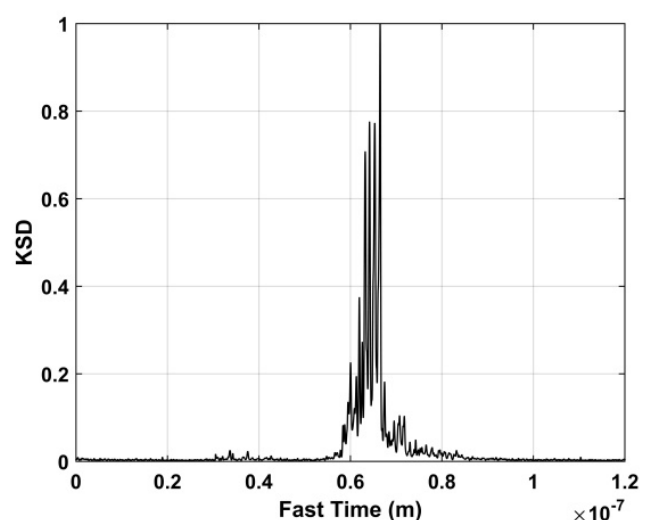

(b)

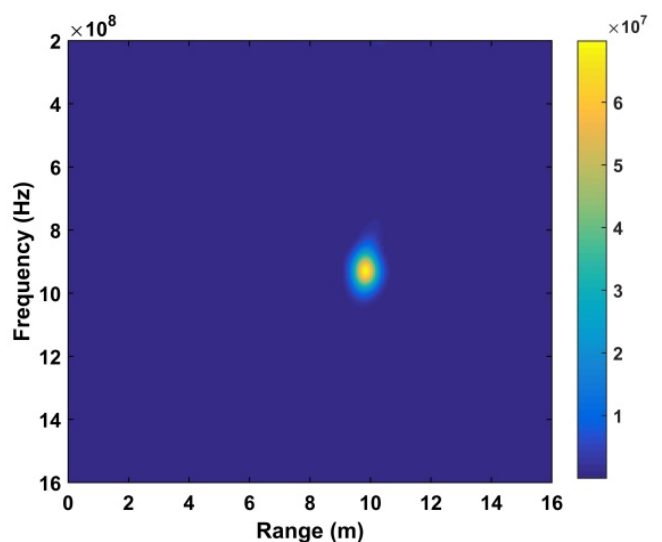

(b)

Fig. 9. The detection results using the actuator (a) KSD values at $600 \mathrm{~cm}$; (b) KSD values at $1000 \mathrm{~cm}$; (c) range estimate at $600 \mathrm{~cm}$; (d) range estimate at $1000 \mathrm{~cm}$.

Table 4. Parameter estimates based on two different methods

\begin{tabular}{|c|c|c|}
\hline Method & FFT & Proposed \\
\hline \hline 0.1155 & 0.3337 & 954 \\
\hline-31.08 & -12.05 & 0.46 \\
\hline 7.38 & 0.18 & -17.26 \\
\hline 65.35 & 0.12 & 20 \\
\hline
\end{tabular}

\section{Conclusion}

A novel noncontact method is proposed in this article for human respiratory movement detection using the through-wall radar. The distance can be determined via analyzing characteristics of life sign based on STFT. The rate of human breathing movement is extracted by employing the multiple spectrum accumulation method. The excellent capability of the developed algorithm is tested via comparing with several references using the dataset in different environments. Results indicate its better ability to improve SNR and remove clutters. Most importantly, the new detection method is easy to be implemented, which can be used to nature disaster relief widely. 


\section{References}

[1] S.D. Liang, "Sense-through-wall human detection based on UWB radar sensors," Signal Processing, vol. 126, pp. 117-124, Sep. 2016. Article (CrossRef Link).

[2] M. Alibakhshikenari, B.S. Virdee and E. Limiti, "Wideband planar array antenna based on SCRLH-TL for airborne synthetic aperture radar application,” Journal of Electromagnetic Waves and Applications, vol. 32, no. 12, pp. 1-14, May 2018. Article (CrossRef Link).

[3] H.S. Cho, Y.J. Park, H.K. Lyu, et al., "Novel Heart Rate Detection Method Using UWB Impulse Radar,” Journal of Signal Processing Systems, vol. 87, no. 2, pp. 229-239, May 2017. Article (CrossRef Link).

[4] A. Mohammad, S.V. Bal, K. Mohsen, et al., "Beam-scanning leaky-wave antenna based on CRLH-metamaterial for millimetre-wave applications,” IET Microwave Antenna and Propagation, 2019. Article (CrossRef Link).

[5] W. Hung, C. Chang and T. Lee, "Real-Time and Noncontact Impulse Radio Radar System for mu m Movement Accuracy and Vital-Sign Monitoring Applications,” IEEE Sensors Journal, vol. 17, no. 8, pp. 2349-2358, Feb. 2017. Article (CrossRef Link).

[6] Y. Nijsure, W. Tay, E. Gunawan, et al., "An impulse radio ultrawideband system for contactless noninvasive respiratory monitoring,” IEEE Transactions on Biomedical Engineering, vol. 60, no. 6, pp. 1509-1517, Jan. 2013. Article (CrossRef Link).

[7] A. Mohammad, B.S. Virdee, A. Abdul, et al. "A novel monofilar-Archimedean metamaterial inspired leaky-wave antenna for scanning application for passive radar systems," Microwave and Optical Technology Letters, vol. 60, no. 8, pp. 2055-2060, 2018. Article (CrossRef Link).

[8] E. Limiti, M. Alibakhshi-Kenari, B.S. Virdee, et al., "Periodic array of complementary artificial magnetic conductor metamaterials-based multiband antennas for broadband wireless transceivers," IET Microwaves, Antennas \& Propagation, vol. 10, no. 15, pp. 1682-1691, Dec. 2016. Article (CrossRef Link).

[9] W. Hu, Z. Zhao, Y. Wang, et al., "Noncontact accurate measurement of cardiopulmonary activity using a compact quadrature Doppler radar sensor,” IEEE Transactions on Biomedical Engineering, vol. 61, no. 3, pp. 725-735, Nov. 2016. Article (CrossRef Link).

[10] C. Gu, C. Li, "Assessment of human respiration patterns via noncontact sensing using doppler multi-radar system,” Sensors, vol. 15, no. 3, pp. 6383-6398, Mar. 2015. Article (CrossRef Link).

[11] A. Lazaro, D. Girbau, and R. Villarino, "Techniques for clutter suppression in the presence of body movements during the detection of respiratory activity through UWB radars,” Sensors, vol. 14, no. 2, pp. 2595-2618, Feb. 2014. Article (CrossRef Link).

[12] C. Li, F. Chen, J. Jin, et al., "A Method for Remotely Sensing Vital Signs of Human Subjects Outdoors,” Sensors, vol. 15, no. 7, pp. 14830-14844, 2015. Article (CrossRef Link).

[13] R.A. Sadeghzadeh, M. Alibakhshi-Kenari and M. Naser-Moghadasi, "UWB antenna based on SCRLH-TLs for portable wireless devices,” Microwave and Optical Technology Letters, vol. 58, no. 1, pp. 69-71, Jan. 2016. Article (CrossRef Link)

[14] M.C. Huang, J. Liu, W. Xu, et al., “A self-calibrating radar sensor system for measuring life signs,” IEEE Transactions on Biomedical Circuits and Systems, vol. 10, no. 2, pp. 352-363, May 2015. Article (CrossRef Link).

[15] F. JalaliBidgoli, S. Moghadami and S.A. Ardalan, "Compact Portable Microwave Life-Detection Device for Finding Survivors,” IEEE Embedded Systems Letters, vol. 8, no. 1, pp. 10-13, Mar. 2016. Article (CrossRef Link).

[16] G. Gennarelli, G. Ludeno and F. Soldovieri, "Real-Time Through-Wall Situation Awareness Using a Microwave Doppler Radar Sensor,” Remote Sensing, vol. 8, no. 8, p. 621, Jul. 2016. Article (CrossRef Link).

[17] C. Li, F. Chen, F. Qi, et al., "Searching for survivors through random human-body movement outdoors by continuous-wave radar array,” PLoS ONE, vol. 11, no. 4, p. e0152201, Apr. 2016, Article (CrossRef Link). 
[18] E. Pittella, B. Zanaj, S. Pisa, et al., "Measurement of Breath Frequency by Body-Worn UWB Radars: A Comparison Among Different Signal Processing Techniques,” IEEE Sensors Journal, vol. PP, no. 99, pp. 1772-1780, Jan. 2017.Article (CrossRef Link).

[19] M. He, Y.J. Nian and Y.S. Gong, "Novel signal processing method for life sign monitoring using FMCW radar,” Biomedical Signal Processing and Control, vol. 33, pp. 335-345, Mar. 2017. Article (CrossRef Link).

[20] V.T. Vu, T.K. Sjogren, M.I. Pettersson, et al., "Detection of moving targets by focusing in UWB SAR theory and experimental results," IEEE Transactions on Geoscience and Remote Sensing, vol. 48, no. 10, pp. 3799-3815, Nov. 2010. Article (CrossRef Link).

[21] X. Zhuge and A. Yarovoy, "A sparse aperture MIMO-SAR based UWB imaging system for concealed weapon detection,” IEEE Transactions on Geoscience and Remote Sensing, vol. 49, no. 1, pp. 509-518, Feb. 2011. Article (CrossRef Link).

[22] M. Ascione, A. Buonanno, M. D'Urso, et al., "A new measurement method based on music algorithm for through-the-wall detection of life signs," IEEE Transactions on Instrumentation and Measurement, vol. 62, no. 1, pp. 13-26, Jan. 2013. Article (CrossRef Link).

[23] L. Liu, Z. Liu and B. Barrowes, "Through-wall bio-radiolocation with UWB impulse radar-Observation, simulation and signal extraction," IEEE Journal of Selected Topics in Applied Earth Observations and Remote Sensing, vol. 4, no. 4, pp.791-798, Jan. 2012. Article (CrossRef Link).

[24] L. Liu, Z. Liu, H. Xie, et al., "Numerical simulation of UWB impulse radar life sign detection at an earthquake disaster site,” Ad Hoc Networks, vol. 13, pp. 34-41, Feb. 2014. Article (CrossRef Link).

[25] J. Wang, X. Wang, L. Chen, et al., "Noncontact distance and amplitude-independent vibration measurement based on an extended DACM algorithm," IEEE Transactions on Instrumentation and Measurement, vol. 63, no. 1, pp. 145-153, Jan. 2014. Article (CrossRef Link).

[26] Z. Li, W. Li, H. Lv, et al., “A novel method for respiration-like clutter cancellation in life detection by dual-frequency IR-UWB radar,” IEEE Transactions on Microwave Theory and Techniques, vol. 61, no. 5, pp. 2086-2092, May 2013. Article (CrossRef Link).

[27] X. Liang, H. Zhang, T.A. Gulliver, et al., “An Improved Algorithm for Through-wall Target Detection Using Ultra-wideband Impulse Radar,” IEEE Access, vol. PP, no. 99, pp. 22101-22118 Oct. 2017. Article (CrossRef Link)

[28] E. Conte, A. Filippi and S. Tomasin, "ML period estimation with application to life sign monitoring,” IEEE Signal Processing Letters, vol. 17, no. 11, pp. 905-908, Dec. 2010. Article (CrossRef Link).

[29] A. Nezirovíc, A. Yarovoy and L. Ligthart, "Signal processing for improved detection of trapped victims using UWB radar,” IEEE Transactions on Geoscience and Remote Sensing, vol. 48, no. 4, pp. 2005-2014, May 2010. Article (CrossRef Link).

[30] H. Lv, F. Qi, Y. Zhang, et al., "Improved Detection of Human Respiration Using Data Fusion Basedon a Multistatic UWB Radar,” Remote Sensing, vol. 8, no. 9, p. 773, Sep. 2016. Article (CrossRef Link).

[31] Y. Wang, Q. Liu and A.E. Fathy, "CW and pulse-Doppler radar processing based on FPGA for human sensing applications,” IEEE Transactions on Geoscience and Remote Sensing, vol. 51, no. 5, pp. 3097-3107, May 2013. Article (CrossRef Link).

[32] Z. Zhang, X. Zhang, H. Lv, et al., "Human-target detection and surrounding structure estimation under a simulated rubble via UWB radar,” IEEE Geoscience and Remote Sensing Letters, vol. 10, no. 2, pp. 328-331, Mar. 2013. Article (CrossRef Link).

[33] X. Liang, H. Zhang, T.A. Gulliver, et al., "Improved Denoising Method for Through-wall Life sign Detection Using UWB Impulse Radar,” Digital Signal Processing, vol. 74, pp. 72-93, Dec. 2017. Article (CrossRef Link).

[34] X. Liang and H. Zhang, "Remotely detectable signs of life based on impulse UWB radar," Multimedia Tools and Applications, vol. 78, no. 8, pp. 10583-10599, Apr. 2019. Article (CrossRef Link). 
[35] A. Nezirovic, A.G. Yarovoy and L.P. Ligthart, "Signal processing for improved detection of trapped victims using UWB radar," IEEE Transactions on Geoscience and Remote Sensing, vol. 48, no. 4, pp. 2005-2014, May 2010. Article (CrossRef Link).

[36] X. Liang, H. Zhang, T.A. Gulliver, et al., "Through-wall Human Being Detection Using UWB Impulse Radar," EURASIP Journal on Wireless Communications and Networking, no. 46, pp. 1-17 Dec. 2018. Article (CrossRef Link).

[37] Y. Xu, S. Wu, C. Chen, et al., "Life sign detection method based on multiple higher order cumulant for ultra-wideband radar," IEEE Transactions on Geoscience and Remote Sensing, vol. 50, no. 99, pp. 1-12, Ap. 2012. Article (CrossRef Link).

[38] X. Hu and T. Jin, "Short-Range Life signs Sensing Based on EEMD and CWT Using IR-UWB Radar,” Sensors, vol. 16, p. 2025, Aug. 2016. Article (CrossRef Link).

[39] C. LI and J. Lin, "Random body movement cancellation in Doppler radar vital sign detection," IEEE Transactions on Microwave Theory and Techniques, vol. 56, no. 12, pp. 3143-3152, Jan. 2009. Article (CrossRef Link).

[40] B.K. Park, O. Boric-Lubecke and V.M. Lubecke, "Arctangent demodulation with DC offset compensation in quadrature Doppler radar receiver systems," IEEE Transactions on Microwave Theory and Techniques, vol. 55, no. 5, pp. 1073-1079, Jun. 2007. Article (CrossRef Link).

[41] K. Naishadham and J.E. Piou, "A robust state space model for the characterization of extended returns in radar target signatures," IEEE Transactions on Antennas and Propagation, vol. 56, no. 6, pp. 1742-1751, Jul. 2008. Article (CrossRef Link).

[42] Z. Wu and N.E. Huang, "A study of the characteristics of white noise using the empirical mode decomposition method," Proceedings of The Royal Society A Mathematical Physical and Engineering Sciences, vol. 460, no. 2046, pp. 1597-1611, Jun. 2004. Article (CrossRef Link).

[43] Z. Wang, H. Zhang, T. Lu, et al., "A new range-free localisation in wireless sensor networks using support vector machine,” International Journal of Electronics, vol. 105, no. 2, pp. 244-261, Feb. 2018. Article (CrossRef Link).

[44] J. Antoni, "The spectral kurtosis: a useful tool for characterising non-stationary signals," Mechanical Systems and Signal Processing, vol. 20, no. 2, pp. 282-307, Feb. 2006. Article (CrossRef Link).

[45] R. Crochiere, "A weighted overlap-add method of short-time Fourier analysis/Synthesis," IEEE Transactions on Acoustics Speech and Signal Processing, vol. 28, no. 1, pp. 99-102, Mar. 1980. Article (CrossRef Link).

[46] B. Allen, "Short Term Spectral Analysis, Synthesis, and Modification by Discrete Fourier Transform," IEEE Transactions on Acoustics Speech and Signal Processing, vol. 25, no. 3, pp. 235-238, Jul. 1977. Article (CrossRef Link).

[47] K. Wójcicki, M. Milacic, A. Stark, et al., "Exploiting Conjugate Symmetry of the Short-Time Fourier Spectrum for Speech Enhancement,” IEEE Signal Processing Letters, vol. 15, pp. 461-464, Feb. 2008. Article (CrossRef Link).

[48] L. Marple, "Computing the Discrete-Time "Analytic" Signal via FFT," IEEE Transactions on Signal Processing, vol. 47, no. 9, pp. 2600-2603, Oct. 1999. Article (CrossRef Link). 


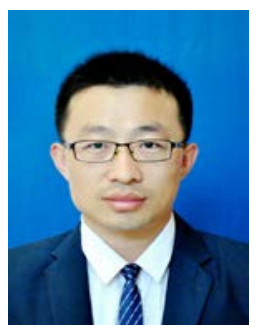

Xiaolin Liang was born in Shandong, China, in 1988. He received the B.S. degree in electronic and information engineering from Qilu University of Technology (Shandong Academy of Sciences), China, in 2012, and the Ph.D. degree in intelligent information and communication system from the Ocean University of China, in 2018. From 2016 to 2017, he worked in the Key Laboratory of Electromagnetic Radiation and Sensing Technology, Institute of Electronics, Chinese Academy of Science. He now works in the 41st research institute of China Electronic Technology Corporation. His research interests include UWB positioning systems, mm-wave systems, UWB radar, vital sign detection, THz radar, UAV detection, and spread spectrum communications. Dr. Liang now is the reviewer of several journals including IEEE Access, IET Radar Sonar and Navigation, Wireless Personal Communications, IET Communications, etc.

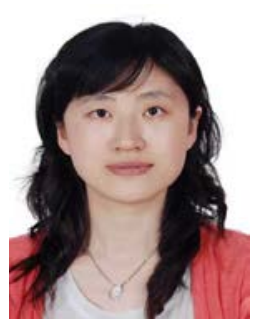

Yongling Jiang is an associate professor of Fundamental Computer Department, Ocean University of China. Her current research interests include automatic identification technology and UWB radar. She is engaged in computer education and faculty development as well. 